\title{
Mental health care for adult refugees in high-income countries
}

\author{
D. Giacco and S. Priebe* \\ Unit for Social and Community Psychiatry, WHO Collaborating Centre for Mental Health Service Development), Queen Mary University of \\ London, London, UK
}

\begin{abstract}
Approximately one-third of people who have obtained refugee status live in high-income countries. Over recent years, the number of refugees has been increasing, and there are questions on how many of them need mental health care and which type of interventions are beneficial. Meta-analyses showed highly variable rates of mental disorders in adult refugees. This variability is likely to reflect both real differences between groups and contexts, and methodological inconsistencies across studies. Overall prevalence rates after resettlement are similar to those in host populations. Only post-traumatic stress disorder (PTSD) is more prevalent in refugees. In long-term resettled refugees, rates of anxiety and depressive disorders are higher and linked to poor social integration. Research on mental health care for refugees in high-income countries has been extensive, but often of limited methodological quality and with very context-specific findings. The existing evidence suggests several general principles of good practice: promoting social integration, overcoming barriers to care, facilitating engagement with treatment and, when required, providing specific psychological treatments to deal with traumatic memories. With respect to the treatment of defined disorders, only for the treatment of PTSD there has been substantial refugee-specific research. For other diagnostic categories, the same treatment guidelines apply as to other groups. More systematic research is required to explore how precisely the general principles can be specified and implemented for different groups of refugees and in different societal contexts in host countries, and which specific interventions are beneficial and cost-effective. Such interventions may utilise new communication technologies. Of particular importance are long-term studies to identify when mental health interventions are appropriate and to assess outcomes over several years. Such research would benefit from sufficient funding, wide international collaboration and continuous learning over time and across different refugee groups.
\end{abstract}

Received 7 August 2017; Accepted 24 September 2017; First published online 25 October 2017

Key words: Interventions, mental disorders, refugees, research.

Worldwide, there are 65.3 million forcibly displaced migrants because of persecution, armed conflicts, civil violence and violations of human rights (United Nations High Commissioner for Refugees - UNHCR, 2017a). In the media and much of the scientific literature, all these people are commonly referred to as refugees. Yet, not all of them are formally recognised as refugees, and many are actually asylum seekers or irregular migrants. Obtaining a formal refugee status can be a long and complex process. Approximately one in four of all forcibly displaced migrants have a refugee status (17.2 million). About one-third of those who have obtained such a status live in high-income countries ( $>5$ million; United Nations High Commissioner for Refugees - UNHCR, 2017b).

* Address for correspondence: S. Priebe, Unit for Social and Community Psychiatry, WHO Collaborating Centre for Mental Health Service Development), Queen Mary University of London, London, UK.

(Email: s.priebe@qmul.ac.uk)
As compared to recognised refugees, asylum seekers and irregular migrants may be exposed to additional difficulties and potential stressors in their host countries. They often experience uncertainty about the outcome of their asylum application, can be detained because of not having immigration rights and encounter additional barriers to accessing mainstream health care services or work opportunities (Jensen et al. 2011; Dauvrin et al. 2012; Straßmayr et al. 2012; Bradby et al. 2015; De Vito et al. 2015). Despite these significant differences between different types of forced migrants, we will use the term 'refugees' in this paper as including all groups of forced migrants, as this reflects the common use of the term in public debates and also in much of the research.

The recent increase in the number of refugees in high-income countries - particularly following humanitarian crises in Syria, Eritrea and South Sudan - has renewed a wide interest in what the challenges are to mental health care systems and in evidence on which interventions should be provided to deal with those challenges (Porter \& Haslam, 2005; Priebe et al. 2016). 


\section{The challenge: numbers of adult refugees with mental disorders}

Numerous studies have assessed prevalence rates of mental disorders in refugee groups. Systematic reviews and meta-analyses (Fazel et al. 2005; Bogic et al. 2015) show a substantial variation of the identified prevalence rates of mental disorders in adult refugees across studies. For example, prevalence rates of depressive disorders range from 4 to $44 \%$ and those of anxiety disorders from 3 to $40 \%$ (Fazel et al. 2005; Lindert et al. 2009; Close et al. 2016). Overall, there is no clear evidence that prevalence rates of mental disorders in refugees in the first years after resettlement are in general significantly higher or lower than those in the host population. The only exceptions are rates of post-traumatic stress disorder (PTSD). Meta-analyses suggest they are substantially higher in adult refugees. The prevalence rates of PTSD are around 9\% when considering the studies with higher quality methodologies (Fazel et al. 2005) and $30 \%$ in more comprehensive meta-analyses (Steel et al. 2009), whilst they usually are only between 1 and $3 \%$ in host country populations (Atwoli et al. 2015).

To some extent, these differences are likely to reflect real differences between different groups and different contexts in the host country. Refugee groups vary in their social characteristics, background, education, professional qualification and skills, motivation to flee their country of origin, experiences before and during forced migration, and willingness to settle long term in the host country. There is also a large variation in the contexts in the host country. The cultural, political, economical and social contexts and the acceptance of a given refugee group in host countries also vary substantially and change over time. As a result, refugees cannot be regarded as one homogeneous group, and generalised statements about prevalence rates of mental disorders are problematic.

The variation of prevalence rates across studies does not only reveal real differences, but are also due to inconsistent methodologies. Studies differ in the type of interviewers they use, the methods for assessing mental disorders, and - most importantly - the sampling of refugees. In general, there is a tendency that studies with higher quality methodologies - i.e. random sampling approaches, validated instruments for diagnosis, interviewers who are native speakers of the refugees' language - suggest rather lower rates of mental disorders than studies of poorer quality.

Moreover, the way in which psychological distress is expressed varies across cultures. This complicates the detection of mental disorders in clinical practice and can also affect prevalence rates of mental disorders in studies of refugees from different cultural backgrounds (Kohrt et al. 2014).
Considering all the real differences between refugee groups and the methodological problems of many studies, generalised conclusions need to be cautious.

This conclusion is different for refugees who stay in the host country for more than 5 years' time. In longterm resettled refugees, rates of depressive and anxiety disorders seem to be higher than in the host populations, whilst rates of PTSD rates remain increased (Bogic et al. 2015). In long-term studies, mental disorders are linked to poor social integration, particularly social isolation and unemployment (Bogic et al. 2012, 2015; Priebe et al. 2016). It remains unclear whether higher rates of mental disorders in long-term settled refugees are a result of selection processes - refugees with mental disorders might be more likely to stay for that long in the host country - and to what extent poor social integration is the reason for or the result of mental disorders.

The numbers of refugees with mental disorders depend not only on prevalence rates. They are equally determined by the absolute numbers of refugees that have arrived in the country. Since these absolute numbers are substantial and potentially increasing in many high-income countries, the challenge to health care systems is substantial, even if prevalence rates are not higher than those in the host population. The challenge is not only to have sufficient additional capacity in services, but also to prevent mental disorders on a societal level and to provide health interventions that refugees can and do actually use and that are appropriate and effective.

\section{Principles of good mental health care}

Despite the diversity in the characteristics of refugee groups, the existing evidence - not based on randomised controlled trials but on studies using a range of other quantitative and qualitative methodologies (Spencer 2006; Deville et al. 2011; Priebe et al. 2012; Sandhu et al. 2013; Craig, 2015) - suggests some general principles of good mental health care for refugees. They address social risk factors for mental disorders, barriers to accessing and engaging with services (European Union Agency for Fundamental Rights, 2017), and specific psychological problems. The principles are: promoting social integration in the host country; overcoming barriers to accessing care; maximising engagement with services and providing specialised interventions to cope with traumatic memories, when required (Priebe et al. 2016).

\section{Promoting social integration}

Interventions to promote social integration have focused on education, on reducing social isolation 
and on providing vocational training and work opportunities (Spencer 2006; Beirens et al. 2007; IASC guidelines, 2007; Craig, 2015). Many types of educational programmes have been used, including classes to learn the language of the host country, help to convert the professional qualifications of refugees for acceptance in the host country and vocational training to acquire skills and new professional qualifications. Other interventions have focused on links with local communities through targeted events such as community forums or peer mentorship programme from already integrated members of the same refugee group (Spencer 2006; Beirens et al. 2007; IASC guidelines, 2007; Craig, 2015; Procter et al. 2015).

Initiatives to promote the social integration of refugees can go beyond the remit of mental health care. Yet, they should be promoted and known by clinicians, potentially creating partnerships with social services and non-governmental organisations.

\section{Overcoming barriers to care}

It has been widely reported that refugees can experience multiple barriers to accessing care (Priebe et al. 2016; European Union Agency for Fundamental Rights, 2017). Providing estimates on how many refugees with psychological disorders access mental health care of refugees is extremely difficult as these estimates would vary within groups and based on the treatment gap already existing in the different host countries (Wang et al. 2007; Tomita et al. 2016). As a general point, access to mental health services seems to be lower in recently resettled refugees than in host populations (Gerritsen et al. 2006; Abebe et al. 2017), but might slowly increase over time (7-10 years), to a similar level than the host populations (Brendler-Lindqvist et al. 2014).

For overcoming or reducing barriers to care for newly resettled refugees and overcome or reduce barriers, three approaches have been suggested as important: the establishment of outreach services; the integration of mental, physical and social care; and the provision of information on mental health care entitlements to refugees and clinicians (Deville et al. 2011; Priebe et al. 2013).

Outreach services can engage with refugees, identify people with mental disorders and help them to access mainstream services through information and more direct support, i.e. booking appointments and facilitating referrals to and between services (Giacco et al. 2014; Martinez et al. 2015). The exact configuration of appropriate outreach services depends on the overall organisation of the health and social care system and the available resources in the given country. In some countries, outreach services may be delivered within the main health care system, in others non-governmental organisations can be better placed to take up this role (Priebe et al. 2013; Sandhu et al. 2013).

Good coordination of mental, physical and social care is essential to provide good care for refugees with complex health and social problems, many of whom may not access mental health services directly (McColl \& Johnson, 2006; Jensen et al. 2011; Dauvrin et al. 2012). Yet, the fragmentation of health and social care services is a commonly reported concern in highincome countries (Giacco et al. 2015). Different strategies have been suggested to improve the coordination, usually following one of two models. They either create brokering agencies with the specific purpose of linking inputs from different services or they foster collaboration among existing services through shared protocols and projects (Priebe et al. 2013). There is no evidence that one model is generally superior and preferences for different approaches are based more on national traditions and funding systems than on evidence (Nicaise et al. 2013).

A common problem across high-income countries is that neither refugees themselves nor their clinicians are fully aware of the exact entitlements refugees have to access different types of health care. Such information can help refugees to seek treatment and clinicians to make referrals more appropriately. However, the way in which information is provided can make a difference for how and if the information is taken up (Toar et al. 2009; Giacco et al. 2014). Websites or written information can be enough for some refugees (Giacco et al. 2014; Health 4 all Gate, 2017), whilst for others, who are not fully literate or are more used to communicating orally, information needs to be provided via different media such as videos and through verbal messages (Burnett \& Peel, 2001). Traditional classroom-based approaches are resource intensive and require active engagement but have the advantage that they can help to reduce social isolation too (Ekblad et al. 2012). Whilst such information is important, research has shown that many clinicians - based on their humanitarian values - seek ways for providing treatment for refugees even when there is no legal entitlement (Priebe et al. 2011).

\section{Facilitating engagement with services}

For a number of reasons, clinicians and refugees can struggle to establish a positive therapeutic relationship. Most notably, there are often language barriers and refugees that can have ways to express mental distress - e.g. through physical symptoms or pointing towards supernatural explanations - that are unfamiliar to clinicians in high-income countries. Based on experiences with authorities in the country of origin, 
refugees may also tend to mistrust clinicians in the host country (Priebe et al. 2011; Priebe et al. 2013).

Using interpreters who are trained and qualified fosters a better patient experience (Johansson Blight et al. 2009), and can improve the outcome of psychological treatments (d'Ardenne et al. 2007). Face-toface interpretation for all the possible languages can be expensive and difficult to organise. Telephone interpretation services are increasingly available and can reduce costs (Sandhu et al. 2013; Giacco et al. 2014). Consultations with clinicians who speak the same language but are based elsewhere can be arranged through technology-based tools, such as videoconferencing (Mucic, 2010).

It has been suggested that training in cultural competence can help clinicians to understand different cultures with specific explanatory models and beliefs about psychological distress. Appropriate knowledge and skills of clinicians may facilitate better therapeutic relationships with refugees and help them engage with services (d'Ardenne et al. 2005; Lurie, 2009; van Melle et al. 2014).

\section{Helping to cope with traumatic memories}

When it comes to defined psychiatric treatments, practically all evidence-based guidelines apply to refugees as to any other group. In practice, refugees are likely to receive the full range of psychological and pharmacological treatments that are available in mental health care (Silove et al. 2017), and the evidence base for treatments in given cases can be as problematic as for all other patients.

For the treatment of most psychiatric disorders, there is no research evidence that would be specific to refugees. The exceptions are interventions to help refugees cope with traumatic memories and PTSD, on which specific studies have been conducted (Nosè et al. 2017). The evidence is most promising for the effectiveness of Narrative Exposure Therapy (Crumlish \& O'Rourke, 2010; Gwozdziewycz \& Mehl-Madrona, 2013), although this is based on studies of mostly low methodological quality and only small-to-medium effect sizes. Narrative Exposure Therapy aims to help the patients to develop a chronological narrative of their life story with a focus on the traumatic experiences in order to transform fragmented reports of the traumatic experiences into a coherent narrative (Gwozdziewycz \& Mehl-Madrona, 2013). It has been specifically developed for refugee populations and has not yet been tested in other groups (Crumlish \& O'Rourke, 2010; Gwozdziewycz \& Mehl-Madrona, 2013). Trauma-focused psychosocial interventions also seem to reduce depressive symptoms in people with PTSD (Nosè et al. 2017). Still, the more favourable assessment of Narrative Exposure Therapy differs from guidelines for the treatment of PTSD in non-refugee groups. The guidelines for nonrefugee groups recommend cognitive behavioural therapy with a trauma focus, stress management and Eye Movement Desensitisation and Reprocessing (Tol et al. 2013, 2014), for which the evidence in refugees is inconclusive (Nosè et al. 2017).

Whilst much of research and the professional interest in mental health care for refugees seem to focus on PTSD, strategies for good mental health care for refugees - and for research informing such care - should avoid a sole focus on PTSD for two main reasons.

Firstly, despite PTSD being more frequent in refugees than in the general population, it is not the most frequent mental disorder in refugees. Mood and anxiety disorders have a significantly higher prevalence rate (Fazel et al. 2005; Bogic et al. 2015). Thus, the treatments that refugees need most frequently are for depression, anxiety and other severe or common mental disorders. Not many studies are available on the effectiveness of psychological treatments for depression and anxiety in refugee groups as research has mainly focused on PTSD. Most of these treatments are provided in mainstream services, and the general principles of good mental health care for refugees are more important than specific techniques for treating PTSD. Hence, there is a question whether randomised controlled trials of these interventions are needed specifically for refugee groups or naturalistic and pragmatic evaluations of how refugees access, engage and benefit from these interventions may be more appropriate.

Secondly, whilst most refugees are exposed to events that are stressful and potentially traumatic, only about one in ten of them develop PTSD. Most refugees are able to deal effectively with these experiences and move on with their new life in the host country. Many refugees reveal 'an extraordinary adaptive capacity and strengths, both individual and collective' (Shakespeare-Finch et al. 2014). Those who manage to complete their flight in high-income countries may include particularly resilient and resourceful people, with a chance for 'adaptive growth' in the host country (Papadopoulos, 2006; Priebe et al. 2016). A focus on PTSD may foster a tendency to regard refugees primarily as victims, and underestimate their strength, skills, resilience and potentials.

\section{Future perspectives}

Implementing the principles of good practice requires funding (e.g. for establishing outreach activities), appropriate service organisation (e.g. to improve 
their co-ordination) and staff training (e.g. to work effectively with interpreters). Thus, not all improvements depend exclusively on the availability of financial resources. Yet, all of them probably require a degree of acceptance - if not welcoming - of refugees in the host society rather than a rejecting attitude.

For research, one might argue that there is more evidence about the nature of the problems and less about what exactly mental health care should do to alleviate them. We see three core tasks:

Firstly, longitudinal studies are required that cover periods of several years, preferably going beyond the usual time frame of 3-5 years that most funding bodies apply for awarding research grants. Such long-term studies should explore the course and development of mental distress in different refugee groups over time (Silove et al. 2017). They should identify which selection factors, if any, contribute to the higher prevalence rates of mental disorders in long-term resettled refugees, and disentangle the association of poor social integration and different mental disorders (Burns, 2015). Such evidence should inform strategies as to when refugees should be encouraged to seek professional mental health treatment and when it is more beneficial to trust their resources and social support rather than turn them into psychiatric patients. Longitudinal research should also assess the long-term outcomes of specific interventions, and - although rarely seen as a priority when new groups of refugees arrive - investigate best possible support for the second generation, which either arrived as small children or were already born in the host country.

Secondly, whilst the outlined principles of good mental health care may be widely accepted, they are rather general. So far, they can be illustrated with examples but there is little systematic evidence for which precise interventions are better than others and why. The exact implementation of the principles for different groups and in different contexts requires much more research. Over time, the research community should develop an understanding of how general principles have to be specified depending on the characteristics of the historical, political, economic and social context and how health and social care systems should best respond, in general and for particularly vulnerable subgroups such as refugees who have lost their family and do not have supportive peers in the host country.

Thirdly, new communication technologies should provide an option not only for dealing with language barriers, but much more widely for providing support and interventions (Giacco et al. 2014). Large numbers of refugees in high-income countries use smart phones and the internet (Gillespie et al. 2016), sometimes linking with peers across countries, and there will be potentials for facilitating assessments (Moreno et al. 2012) and developing novel types of face-to-face and virtual interventions (Ünlü Ince et al. 2013).

\section{Conclusions}

The practice of mental health care for refugees across high-income countries varies (Priebe et al. 2011) and includes many positive initiatives. Some improvements should be possible in a short time frame. They require a supportive societal climate, political will and professional clarity about what should be done.

The research agenda represents a long-term task. This long-term perspective needs to be squared with the interest of politicians, who support the funding of research programmes. Faced with the problems of newly arriving groups of refugees, politicians may want research evidence on what to do more or less immediately, an expectation that current research methodologies can rarely satisfy.

Research on refugees would benefit from continuity of studies and closer international collaboration, so that one can learn more from commonalities and differences across countries and situations. Specific research on mental health disorders of and mental health care for refugees may also benefit from interdisciplinary approaches and a closer link to more general research about how different societies respond to refugees and how their attitudes and policies affect shortand long-term outcomes of refugees after their arrival in a host country.

\section{Acknowledgements}

None.

\section{Financial support}

None.

\section{References}

Abebe DS, Lien L, Elstad JI (2017). Immigrants' utilization of specialist mental healthcare according to age, country of origin, and migration history: a nation-wide register study in Norway. Social Psychiatry and Psychiatric Epidemiology 52, 679-687.

Atwoli L, Stein DJ, Koenen KC, McLaughlin KA (2015). Epidemiology of posttraumatic stress disorder: prevalence, correlates and consequences. Current Opinion in Psychiatry 28, 307-311.

Beirens H, Hughes N, Hek R, Spicer N (2007). Preventing social exclusion of refugee and asylum seeking children: building new networks. Social Policy and Society 6, 219. 
Bogic M, Ajdukovic D, Bremner S, Franciskovic T, Galeazzie GM, Kucukalic A, Lecic-Tosevski D, Morina N, Popovski M, Schützwohl M, Wang D, Priebe S (2012). Factors associated with mental disorders in long-settled war refugees: refugees from the former Yugoslavia in Germany, Italy and the UK. British Journal of Psychiatry 200, 216-223.

Bogic M, Njoku A, Priebe S (2015). Long-term mental health of war-refugees: a systematic literature review. BMC International Health and Human Rights 15, 1.

Bradby H, Humphris R, Newall D, Phillimore J (2015). Public health aspects of migrant health: a review of the evidence on health status for refugees and asylum seekers in the European Region. WHO Regional Office for Europe (Health Evidence Network synthesis report 44): Copenhagen.

Brendler-Lindqvist M, Norredam M, Hjern A (2014).

Duration of residence and psychotropic drug use in recently settled refugees in Sweden-a register-based study. International Journal for Equity in Health 13, 122.

Burnett A, Peel M (2001). Health needs of asylum seekers and refugees. British Medical Journal 322, 544-547.

Burns JK (2015). Poverty, inequality and a political economy of mental health. Epidemiology and Psychiatric Sciences 24, 107-113.

Close C, Kouvonen A, Bosqui T, Patel K, O'Reilly D, Donnelly M (2016). The mental health and wellbeing of first generation migrants: a systematic-narrative review of reviews. Global Health 12, 47. doi:10.1186/s12992-016-0187-3.

Craig G (2015). Migration and integration: A local and experiential perspective. University of Birmingham. Retrieved 01/08/2017 from https://www.birmingham.ac.uk/ Documents/college-social-sciences/social-policy/iris/2015/ working-paper-series/IRiS-WP-7-2015.pdf.

Crumlish N, O'Rourke K (2010). A systematic review of treatments for post-traumatic stress disorder among refugees and asylum-seekers. Journal of Nervous and Mental Disease 198, 237-251.

d'Ardenne P, Capuzzo N, Ruaro L, Priebe S (2005). One size fits all? Cultural sensitivity in a psychological service for traumatised refugees. Diversity in Health and Social Care 2, 29-36.

d'Ardenne P, Ruaro L, Cestari L, Fakhoury W, Priebe S (2007). Does interpreter-mediated CBT with traumatized refugee people work? A comparison of patient outcomes in East London. Behavioural and Cognitive Psychotherapy 35, 293-301.

Dauvrin M, Lorant V, Sandhu S, Deville W, Dia H, Dias S, Gaddini A, Ioannidis E, Jensen NK, Kluge U, Mertaniemi R, Puigpinos i Riera R, Sarvary A, Straßmayr C, Mindaugas S, Soares JJF, Welbel M, Priebe S (2012). Health care for irregular migrants: pragmatism across Europe. A qualitative study. BMC Research Notes 5, 99. doi:10.1186/1756-0500-5-99.

Deville W, Greacen T, Bogic M, Dauvrin M, Dias S, Gaddini A, Jensen NK, Karamanidou C, Kluge U, Mertaniemi R, Puigpinos i Riera R, Sarvary A, Soares JJF, Stankunas M, Straszmeyr C, Welbel M, Priebe S (2011). Healthcare for immigrants in Europe: is there still consensus among country experts about principles of good practice? A Delphi study. BMC Public Health 11, 699. doi:10.1186/1471-2458-11-699.
De Vito E, de Waure C, Specchia ML, Ricciardi W (2015). Public Health Aspects of Migrant Health: A Review of the Evidence on Health Status for Undocumented Migrants in the European Region. WHO Regional Office for Europe (Health Evidence Network synthesis report 42): Copenhagen.

Ekblad S, Linander A, Asplund M (2012). An exploration of the connection between two meaning perspectives: an evidence-based approach to health information delivery to vulnerable groups of Arabic- and Somali-speaking asylum seekers in a Swedish context. Global Health Promotion 19, 21-31.

European Agency for Fundamental Rights (2017). Healthcare entitlements of migrants in an irregular situation in the EU-28. Retrieved 05/08/2017 from http://fra. europa.eu/en/theme/asylum-migration-borders/healthcareentitlements.

Fazel M, Wheeler J, Danesh J (2005). Prevalence of serious mental disorder in 7000 refugees resettled in western countries: a systematic review. Lancet 365, 1309-1314.

Gerritsen AA, Bramsen I, Devillé W, van Willigen LH, Hovens JE, van der Ploeg HM (2006). Use of health care services by Afghan, Iranian, and Somali refugees and asylum seekers living in The Netherlands. European Journal of Public Health 16, 394-399.

Giacco D, Matanov A, Priebe S (2014). Providing mental healthcare to immigrants: current challenges and new strategies. Current Opinion in Psychiatry 27, 282-228.

Giacco D, Bird VJ, McCrone P, Lorant V, Nicaise P, Pfennig A, Bauer M, Ruggeri M, Lasalvia A, Moskalewicz J, Welbel M, Priebe S (2015). Specialised teams or personal continuity across inpatient and outpatient mental healthcare? Study protocol for a natural experiment. BMJ Open 5, e008996.

Gillespie M, Ampofo L, Cheesman M, Faith B, Iliadou E, Issa A, Osseiran S, Skleparis D (2016). Mapping Refugee Media Journeys Smartphones and Social Media Networks. Retrieved 05/07/17 from http://www.open.ac.uk/ccig/sites/ www.open.ac.uk.ccig/files/Mapping\%20Refugee\%20Media \%20Journeys\%2016\%20May\%20FIN\%20MG_0.pdf.

Gwozdziewycz N, Mehl-Madrona L (2013) Meta-analysis of the use of narrative exposure therapy for the effects of trauma among refugee populations. The Permanente Journal 17, 70-76. doi:10.7812/TPP/12-058 PMID: 23596375.

Health 4 all Gate (2017). http://uoa.campaign.com.gr/

Inter-Agency Standing Committee (2007). IASC Guidelines on Mental Health and Psychosocial Support in Emergency Settings. Inter-Agency Standing Committee: Geneva. Retrieved 12 June 2017 from http://www.who.int/mental_health/ emergencies/guidelines_iasc_mental_health_psychosocial_ june_2007.pdf.

Jensen NK, Norredam M, Draebel T, Bogic M, Priebe S, Krasnik A (2011). Providing medical care for undocumented migrants in Denmark: What are the challenges for health professionals? BMC Health Services Research 11, 154. doi:10.1186/1472-6963-11-154.

Johansson Blight K, Ekblad S, Lindencrona F, Shahnavaz S (2009). Promoting mental health and preventing mental disorder among refugees in western countries. International Journal of Mental Health Promotion 11, 32-44. 
Kohrt BA, Rasmussen A, Kaiser BN, Haroz EE, Maharjan SM, Mutamba BB, de Jong JT, Hinton DE (2014). Cultural concepts of distress and psychiatric disorders: literature review and research recommendations for global mental health epidemiology. International Journal of Epidemiology 43, 365-406.

Lindert J, Ehrenstein O, Priebe S, Mielck A, Brähler E (2009). Depression and anxiety in labor migrants and refugees - a systematic review and meta-analysis. Social Science and Medicine 69, 246-257.

Lurie I (2009). Psychiatric care in restricted conditions for work migrants, refugees and asylum seekers: experience of the Open Clinic for Work Migrants and Refugees, Israel 2006. Israel Journal of Psychiatry and Related Sciences 46, 172181.

Martinez O, Wu E, Sandfort T, Dodge B, Carballo-Dieguez A, Pinto R, Rhodes SD, Moya E, Chavez-Baray S (2015). Evaluating the impact of immigration policies on health status among undocumented immigrants: a systematic review. Journal of Immigrant and Minority Health 17, 947-970.

McColl H, Johnson S (2006) Characteristics and needs of asylum seekers and refugees in contact with London community mental health teams. Social Psychiatry and Psychiatric Epidemiology 41, 789-795.

Moreno FA, Chong J, Dumbauld J, Humke M, Byreddy S (2012). Use of standard Webcam and Internet equipment for telepsychiatry treatment of depression among underserved Hispanics. Psychiatric Services 63, 1213-1217.

Mucic D (2010). Transcultural telepsychiatry and its impact on patient satisfaction. Journal of Telemedicine and Telecare 16, 237-242.

Nicaise P, Tulloch S, Dubois V, Matanov A, Priebe S, Lorant V (2013). Using social network analysis for assessing mental health and social services inter-organisational collaboration: findings in deprived areas in Brussels and London. Administration and Policy in Mental Health and Mental Health Services Research 40, 331-339.

Nosè M, Ballette F, Bighelli I, Turrini G, Purgato M, Tol W, Priebe S, Barbui C (2017). Psychosocial interventions for post-traumatic stress disorder in refugees and asylum seekers resettled in high-income countries: systematic review and meta-analysis. PLOS ONE 12, e0171030. doi: 10.1371/journal.pone.0171030.

Papadopoulos RK (2006). Refugees and Psychological Trauma: Psychosocial Perspectives. Harvard University Press: Cambridge, MA. Retrieved 12 June 2017 from http://isites. harvard.edu/fs/docs/icb.topic920418.files/arc_1_10refand psych-1.pdf.

Porter M, Haslam N (2005). Predisplacement and postdisplacement factors associated with mental health of refugees and internally displaced persons. Journal of American Medical Association 294, 602-612.

Priebe S, Sandhu S, Dias S, Gaddini A, Greacen T, Ioannidis E, Kluge U, Krasnik A, Lamkaddem M, Lorant V, Puigpinós i Riera R, Sarvary A, Soares JJF, Stankunas M, Straßmayr C, Wahlbeck K, Welbel M, Bogic M (2011). Good practice in health care for migrants: views and experiences of care professionals in 16 European Countries.
BMC Public Health 11, 187-199. http://www.biomedcentral. com/1471-2458/11/187.

Priebe S, Matanov A, Schor R, Straßmayr C, Barros H, Barry MM, Diaz-Ollala JM, Gabor E, Greacen T, Holcnerová $P$, Kluge U, Lorant V, Moskalewicz J, Schene AH, Macassa G, Gaddini A (2012). Good practice in mental health care for socially marginalised groups in Europe: a qualitative study of expert views in 14 countries. BMC Public Health 12, 248. doi: 10.1186/1471-2458-12-248.

Priebe S, Matanov A, Barros H, Canavan R, Gabor E, Greacen T, Holcnerová $P$, Kluge U, Nicaise $P$, Moskalewicz J, Diaz-Olalla JM, Straßmayr C, Schene AH, Soares JJF, Tulloch S, Gaddini A (2013). Mental healthcare provision for marginalized groups across Europe: findings from the PROMO study. European Journal of Public Health 23, 97-103. doi:10.1093/eurpub/ckr214.

Priebe S, Giacco D, El-Nagib R (2016). Public Health Aspects of Migrant Mental Health: A Review of the Evidence on Mental Health Care for Refugees, Asylum Seekers and Irregular Migrants in the European Region. WHO Regional Office for Europe (Health Evidence Network (HEN) Synthesis Report 47): Copenhagen.

Procter N, Williamson P, Gordon A, McDonoughs D (2015). Refugee and asylum seeker self-harm with implications for transition to employment participation - a review.

Suicidology 16, 3.

Sandhu S, Bjerre NV, Dauvrin M, Dias S, Gaddini A, Greacen T, Ioannidis E, Kluge U, Jensen NK, Lamkaddem M, Puigpinós I, Riera R, Kósa Z, Wihlman U, Mindaugas S, Straßmayr C, Wahlbeck K, Welbel M, Priebe S (2013). Experiences with treating immigrants: a qualitative study in mental health services across 16 European countries. Social Psychiatry and Psychiatric Epidemiology 48, 105-116.

Silove D, Ventevogel P, Rees S (2017). The contemporary refugee crisis: an overview of mental health challenges. World Psychiatry 16, 130-139.

Shakespeare-Finch J, Schweitzer RD, King J, Brough M (2014). Distress, coping and posttraumatic growth in refugees from Burma. Journal of Immigrant and Refugee Studies 12, 311-330.

Spencer S (2006). Refugees and other new migrants: a review of the evidence on successful approaches to integration. Centre on Migration, Policy and Society (COMPAS): Oxford, UK. Retrieved 22 June 2017 from https://www.compas.ox.ac.uk/ media/ER-2006-Integration_Refugees_UK_HO.pdf.

Steel Z, Chey T, Silove D, Marnane C, Bryant RA, van Ommeren M (2009). Association of torture and other potentially traumatic events with mental health outcomes among populations exposed to mass conflict and displacement: a systematic review and meta-analysis. JAMA 302, 537-549.

Straßmayr C, Matanov A, Priebe S, Barrow H, Canavan R, Diaz-Olalla JM, Gabor E, Gaddini A, Greacen T, Holcnerová P, Kluge U, Welbel M, Nicaise P, Schene AH, Soares JJF, Katschnig H (2012). Mental health care for irregular migrants in Europe: barriers and how they are overcome. BMC Public Health 12, 367. doi:10.1186/14712458-12-367. 
Toar M, O'Brien KK, Fahey T (2009). Comparison of selfreported health and healthcare utilisation between asylum seekers and refugees: an observational study. BMC Public Health 9, 214.

Tol WA, Barbui C, Van Ommeren M (2013). Management of acute stress, PTSD, and bereavement: WHO

recommendations. Journal of the American Medical Association 310, 477-478. doi: 10.1001/jama.2013.166723 PMID: 23925613

Tol WA, Barbui C, Bisson J, Cohen J, Hijazi Z, Jones L, de Jong JT, Magrini N, Omigbodun O, Seedat S, Silove D, Souza R, Sumathipala A, Vijayakumar L, Weissbecker I, Zatzick D, van Ommeren M (2014). World Health Organization guidelines for management of acute stress, PTSD, and bereavement: key challenges on the road ahead. PLoS Medicine 11, e1001769. doi:10.1371/journal. pmed.1001769 PMID: 25514024

Tomita A, Kandolo KM, Susser E, Burns JK (2016). Use of short messaging services to assess depressive symptoms among refugees in South Africa: implications for social services providing mental health care in resource-poor settings. Journal of Telemedicine and Telecare 22, 369-377.

United Nations High Commissioner for Refugees (2017a). The UN Refugee Agency. Figures at a glance. Retrieved 25
June 2017 from http://www.unhcr.org/figures-at-a-glance. html.

United Nations High Commissioner for Refugees (2017b). Global trends - forced displacement in 2016. Retrieved 25 June 2017 from http://www.unhcr.org/globaltrends2016/.

Ünlü Ince B, Cuijpers P, van 't Hof E, van Ballegooijen W, Christensen H, Riper H (2013). Internet-based, culturally sensitive, problem-solving therapy for Turkish migrants with depression: randomized controlled trial. Journal of Medical Internet Research 15, e227.

van Melle MA, Lamkaddem M, Stuiver MM, Gerritsen AA, Devillé WL, Essink-Bot M-L (2014). Quality of primary care for resettled refugees in the Netherlands with chronic mental and physical health problems: a cross-sectional analysis of medical records and interview data. BMC Family Practice 15, 160.

Wang PS, Aguilar-Gaxiola S, Alonso J, Angermeyer MC, Borges G, Bromet EJ, Bruffaerts R, de Girolamo G, de Graaf R, Gureje O, Haro JM, Karam EG, Kessler RC, Kovess V, Lane MC, Lee S, Levinson D, Ono $Y$, Petukhova M, Posada-Villa J, Seedat S, Wells JE (2007). Use of mental health services for anxiety, mood, and substance disorders in 17 countries in the WHO world mental health surveys. Lancet 370, 841-850. 